Enfermagem Brasil 2018;17(6):559-60

https://doi.org/10.33233/eb.v17i6.2718

\title{
EDITORIAL \\ Cuidados críticos em risco iminente de morte e ensino à distância de enfermagem: paralelos que sinalizam o óbvio
}

Prof. Dr. Wiliam César Alves Machado

Enfermeiro, Professor Adjunto, Departamento de Enfermagem Fundamental, Escola de Enfermagem Alfredo Pinto (EEAP), UNIRIO, Professor na Faculdade Univértix de Três Rios (UNIVÉRTIX)

Correspondência: E-mail: wilmachado@uol.com.br

A revogação do Decreto 8.754/2016 [1], que incluía a Enfermagem entre os cursos de graduação que dependiam de prévia manifestação do Conselho Nacional de Saúde para autorização do Ministério da Educação, foi de fato um retrocesso, cujos reflexos negativos haveremos de constatar em futuro próximo. O emblemático episódio de atentado ao candidato e presidente eleito do Brasil, evidenciou a importância do cuidado de enfermagem prestado por profissionais qualificados e com expertise na assistência integral da pessoa em risco iminente de morte. Caso as equipes de enfermagem da Santa Casa de Misericórdia de Juiz de Fora, ou do Hospital Albert Einstein, em São Paulo, não fossem compostas por profissionais bacharéis egressos de cursos presenciais, não haveria como garantir plenas possibilidades de recuperação do presidente eleito.

A partir do momento em que o Decreto 8.754/2016 [1] foi revogado pelo Decreto 9.235/2017 [2], teve início a proliferação desordenada de cursos de graduação em Enfermagem de baixa qualidade, agora, amplamente oferecidos na modalidade ensino à distância (ED). Os parlamentares da Comissão de Educação da Câmara demonstraram profundo desconhecimento sobre as especificidades do processo pedagógico da formação técnico-científica do enfermeiro, tampouco se dispuseram a convocar experts de cada uma das suas subáreas de atuação para Ihes prestar assessoria. Esqueceram-se do fato de quando submetidos aos mais diversos procedimentos hospitalares de internação clínica ou cirúrgica, todos procuramos identificar a capacitação dos profissionais que nos prestam cuidados, buscando visualizar e ler o que nos possa informar os dados contidos em seus crachás. Negligenciaram, por desconhecimento, o papel decisivo do enfermeiro como responsável imediato pelo cuidado de alta complexidade prestado às pessoas que experimentam situações que requeiram maior domínio de conhecimentos e habilidades para o desempenho de cuidados críticos, além de desconexão com a realidade dos serviços públicos de saúde oferecidos à população brasileira [3].

A aplicação do princípio da integralidade na relação pedagógica é condição sine qua non para a construção da identidade profissional e pessoal do futuro enfermeiro, contudo, com limitadas possibilidades de êxito na modalidade ED para sua formação profissional [4]. É no campo configurado pela presença de um professor diante de seus alunos, expondo conteúdos teóricos e suas dimensões operacionais, contextualizando tais abordagens com suas experiências de cuidar, que se constroem oportunidades de transferência de constructos. Primeiramente do professor que fala, e depois dos alunos, quando estes começam a falar e a ser ouvidos pelo professor [5]. Acredita-se que, ao ser diretamente apresentado às situações de cuidado e assistência de Enfermagem pautadas no princípio da integralidade, 0 bacharelando se torne mais propenso a introduzir tal prática em sua futura atuação profissional [4].

Não há dúvida que uma aula virtual não pode ter intensidade similar à de uma aula presencial, quando a relação professor-aluno é essencialmente imediata, sem intermediações, e descreve uma situação de tangível transferência entre professor e aluno [5]. Relação de transferência de extrema relevância no ensino presencial de Enfermagem, fundamentalmente calcada no respeito às necessidades humanas básicas afetadas e vulnerabilidades multidimensionais do outro, compreendido como expressão da imagem e semelhança de Deus [6]. 
Não me parece sensato atribuir equivalência entre a sistemática dinâmica presencial de práticas repetitivas de procedimentos de cuidados simulados em laboratórios de técnicas, até que os estudantes alcancem domínio e habilidades para seu seguro desempenho, com quaisquer estratégias de ensino à distância que se proponham envolvimento de cuidados na multidimensionalidade das necessidades humanas. Evidente que as práticas simuladas em laboratórios de técnicas de Enfermagem são desenvolvidas em manequins, porém, transcorridas em ambientes propícios à criação de atmosferas respeitosas, como se estivéssemos diante dos clientes nos diversos campos de prática profissional [7].

Ademais, é fundamental compreender que a formação profissional do enfermeiro deve ser focada no trabalho em equipe, como estratégia pedagógica de preparo para suas futuras atuações nos campos de prática assistencial. Nesse sentido, a aprendizagem colaborativa destaca vantagens em dois níveis: individual e grupal. No primeiro, ela pode contribuir para: ampliar e/ou construir as competências sociais, de integração e comunicação efetivas; incentivar o desenvolvimento do pensamento crítico e a abertura mental; conhecer diferentes temas e adquirir nova informação; reforçar a ideia de que a aprendizagem emerge do diálogo ativo entre professores e alunos; diminuir os sentimentos de isolamento e de temor à crítica; e, finalmente, aumentar a segurança em si mesmo, a autoestima e a integração no grupo [8].

\section{Referências}

1. Brasil. Decreto № 8.754, de 10 de maio de 2016. Altera o Decreto o 5.773 , de 9 de maio de 2006, que dispõe sobre o exercício das funções de regulação, supervisão e avaliação de instituições de educação superior e cursos superiores de graduação e sequenciais no sistema federal de ensino. Disponível em: http://www2.camara.leg.br/legin/fed/decret/2016/decreto-8754-10-maio-2016-783053publicacaooriginal-150314-pe.html

2. Brasil. Decreto № 9.235, de 15 de dezembro de 2017. Dispõe sobre o exercício das funções de regulação, supervisão e avaliação das instituições de educação superior e dos cursos superiores de graduação e de pós-graduação no sistema federal de ensino. Disponível em: http://www.planalto.gov.br/ccivil_03/_Ato20152018/2017/Decreto/D9235.htm

3. Machado DA, Figueiredo NMA, Velasques LS, Bento CAM, Machado WCA, Vianna LAM. Cognitive changes in nurses working in intensive care units. Rev Bras Enferm 2018;71(1):73-9. https://doi.org/10.1590/0034-7167-2016-0513

4. Lima MM, Reibnitz KS, Prado ML, Kloh D. Integralidade como princípio pedagógico na formação do enfermeiro. Texto Contexto Enferm 2013;22(1):106-13.

5. Patto MHS. O ensino a distância e a falência da educação. Educ Pesqui 2013;39(2):303-18. https://doi.org/10.1590/s1517-97022013000200002

6. Machado WCA, Scramin AP. Cuidado multidimensional para e com pessoas tetraplégicas: Re-pensando o cuidar em enfermagem. Revista Ciência, Cuidado e Saúde 2005;4(2):189-97.

7. Figueiredo NMA, Machado WCA (Eds). Tratado de Cuidados de Enfermagem. São Paulo: Roca; 2012.

8. Aciole GG. Rupturas paradigmáticas e novas interfaces entre educação e saúde. Cad Pesqui 2016;46(162):1172-91. https://doi.org/10.1590/198053143528. 